B022

\title{
The Tellus Airborne Geophysical Survey of Northern Ireland
}

\author{
D. Beamish* (British Geological Survey) \& H. Leväniemi (Geological \\ Survey of Finland)
}

DOI: $10.3997 / 2214-4609.201402628$

\section{SUMMARY}

This paper describes an airborne geophysical survey of Northern Ireland that is being conducted over a two year period. Measurements from a fixed-wing aircraft operating at $56 \mathrm{~m}$ include magnetic (gradiometer), radiometric and frequency-domain electromagnetic. The survey will complete over 80,000 line-km of coverage in the summer of 2006. The Phase 1 data, described here, comprise $\sim 47,000$ line-km obtained across the western and central areas of the province. The nature of acquiring geophysical data, at high resolution (200 $\mathrm{m}$ line spacing) in populated areas is distinct from that of other exploration contexts. The survey is being coordinated and conducted alongside a high public profile. The initial Phase 1 Tellus survey results have exceeded expectations. They have excited the interest of the planning, mineral and environmental communities. 


\section{Introduction}

The Tellus airborne geophysical survey of Northern Ireland is being conducted over a two year period by the Joint Airborne geoscience Capability (JAC). This facility, formed by the Finnish and British Geological Surveys (GTK and BGS), provides both partners with a costeffective means of acquiring high-resolution airborne data for their national strategic science programmes. Northern Ireland was the first part of the UK to conduct an independent costbenefit analysis and recognise the benefits of modern, high-resolution aerogeophysical surveying. The survey is funded by the Department of Enterprise, Trade and Investment. In a sign of the times, the project was given the brand-name 'Tellus' by a public-relations company to fulfil a requirement for public outreach and to accommodate public understanding of science. This aspect of the project, although out with the JAC, has been a remarkable success. The Tellus project was conceived as a Resource and Environmental Survey for the benefit of both public and private development sectors. The derived datasets can be used to support government policy decisions in economic and sustainable development, social infrastructure, environment and human health. The 3 main geophysical measurements (magnetic, radiometric and electromagnetic) obtained by the JAC Twin-Otter contribute to different aspects of these broad objectives. The present report describes interim (block-based) data, acquired during the first year of the project.

\section{The 2005 Phase 1 survey}

The geopolitical landmass of Northern Ireland covers an area of $14,160 \mathrm{~km}^{2}$. In order to optimise survey line lengths, the area was divided into 5 blocks, labelled A and B (in the west) and C, D and E covering the central and easternmost sectors. The Phase 1 survey of 2005, acquired 49,800 line-km of data in 83 operational days. The survey parameters are summarised in Table 1.

\begin{tabular}{|l|l|}
\hline Survey line spacing & $200 \mathrm{~m}$ \\
\hline Survey line direction & 345 degrees \\
\hline Tie line spacing (trial) & $2000 \mathrm{~m}$ \\
\hline Tie-line direction & 75 degrees \\
\hline Minimum survey altitude (rural) & $56 \mathrm{~m}$ \\
\hline Minimum survey altitude (other) & $244 \mathrm{~m}$ \\
\hline Typical survey speed & $70 \mathrm{~m} / \mathrm{s}$ \\
\hline Magnetic sampling & $0.1 \mathrm{sec}$ \\
\hline Electromagnetic sampling (3 and 14 kHz) & $0.25 \mathrm{sec}$ \\
\hline Radiometric sampling & $1 \mathrm{sec}$ \\
\hline GPS positional sampling & $1 \mathrm{sec}$ \\
\hline Magnetic/GPS base station sampling & $1 \mathrm{sec}$ \\
\hline PHASE 1 survey duration & $01 \mathrm{July}$ to 05 October 2005 \\
\hline Total line-km acquired (ideal 'trimmed' lines) & $47,608 \mathrm{~km}$ \\
\hline
\end{tabular}

Table 1. Survey parameters of the Tellus PHASE 1 survey.

A complete description of the airborne system and the processing methods used by JAC is given by Hautaneimi et al. (2005). Recently introduced research items include a laser altimeter recording at $200 \mathrm{~Hz}$ and a downward-looking digital video to record continuous, overlapping image frames. These frames can be data-based and, as such, they can provide 


\section{Near Surface}

detailed information on the geophysical responses observed. The 2 frequency EM system has been superseded by a new 4 frequency system that will operate during Phase 2 of the project.

The nature of acquiring large scale airborne geophysical data sets in populated areas such as western Europe, is distinct from many exploration contexts. Low level airborne surveying in the UK requires a framework of planning and consent. Surveying at a height of $56 \mathrm{~m}$, every $200 \mathrm{~m}$, ensures we are highly visible to the population at large. The Tellus operations are therefore supported by a major programme of public awareness. A telephone hot-line is manned by trained professionals (out with the survey operations). Scientific and educational outreach is a component part of the project. Although expensive, these activities provide a direction that our projects will increasingly have to embrace.

Modern surveys provide data that often supersede existing national geophysical data sets. In the case of Northern Ireland, only vintage magnetic data exist. The radiometric and electromagnetic (conductivity) data effectively form new information. The following sections describe the interim geophysical results obtained across one of the 5 survey blocks.

\section{Magnetic data}

The existing onshore airborne magnetic data were acquired in 1959, using $2 \mathrm{~km}$ flight lines at an altitude of 1000 feet.
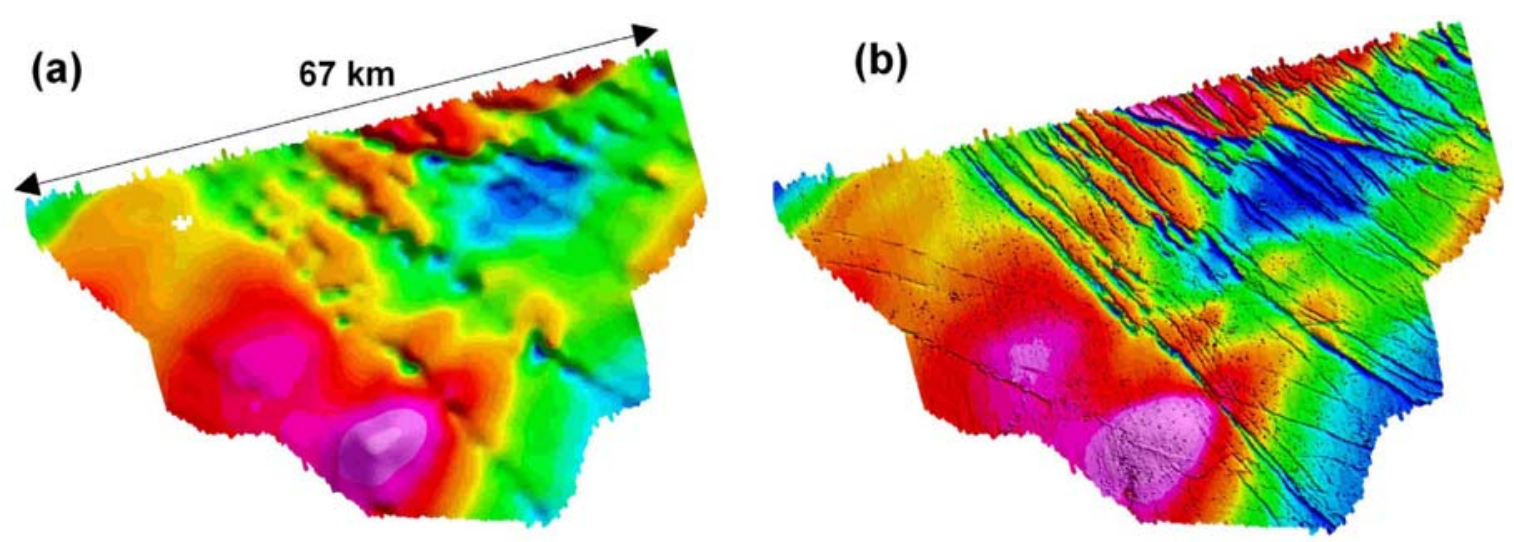

Figure 1. Existing (a) and new (b) airborne magnetic survey data from one of the five Tellus survey blocks (Block B).

The existing (1959) airborne magnetic data set for one of the survey blocks (Block B) is shown in Figure 1a. The equivalent magnetic survey data obtained during the Phase 1 Tellus survey is compared in Figure 1b. It is evident that the decrease in flight line spacing (by a factor of 10), the much lower flight altitude (typically a factor of 5 decrease) coupled with the use of modern Caesium magnetic sensors, brings about new insights into structural associations. Large scale variations are obviously reflected in both data sets. A geological map is shown in Figure 2a. The variations observed largely relate to concealed magnetic basement features. The prominent belt of positive anomalies in the west, are probably early Palaeozoic volcanic rocks, below the Carboniferous basin cover. The extensive dyke swarms, their trends and offsets, very evident in the new data, were unresolved by the vintage data. Also evident in the new data are large numbers of 'pimple anomalies' that represent cultural perturbations (many are individual farm buildings with metal structures/roofs). The removal of such features (magnetic deculturing) is a major issue for surveys in populated regions. 


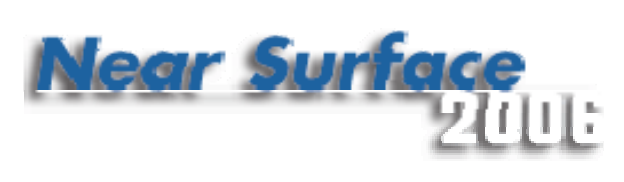

\section{Radiometric data}

Gamma ray spectroscopy principally involves the detection of the 3 natural radionuclide elements Potassium (K-40), Thorium (Th-232) and Uranium (U-238) across an energy bandwidth from 0.04 to $3 \mathrm{MeV}$. The major portion of gamma radiation is derived from the upper $30 \mathrm{~cm}$ of the subsurface. When soil horizons are present, the data may reflect either soil physical properties (e.g. grain size and moisture content) or parent (bedrock derived) properties or combinations of both. Radiometric data are also used in base-metal exploration contexts. For example, $\mathrm{K}$ has been shown to be the most reliable pathfinder in airborne gamma ray surveys, in locating hydrothermal ore deposits, especially gold (Hoover and Pierce, 1990). At present only two economic deposits of gold are being worked in Northern Ireland.
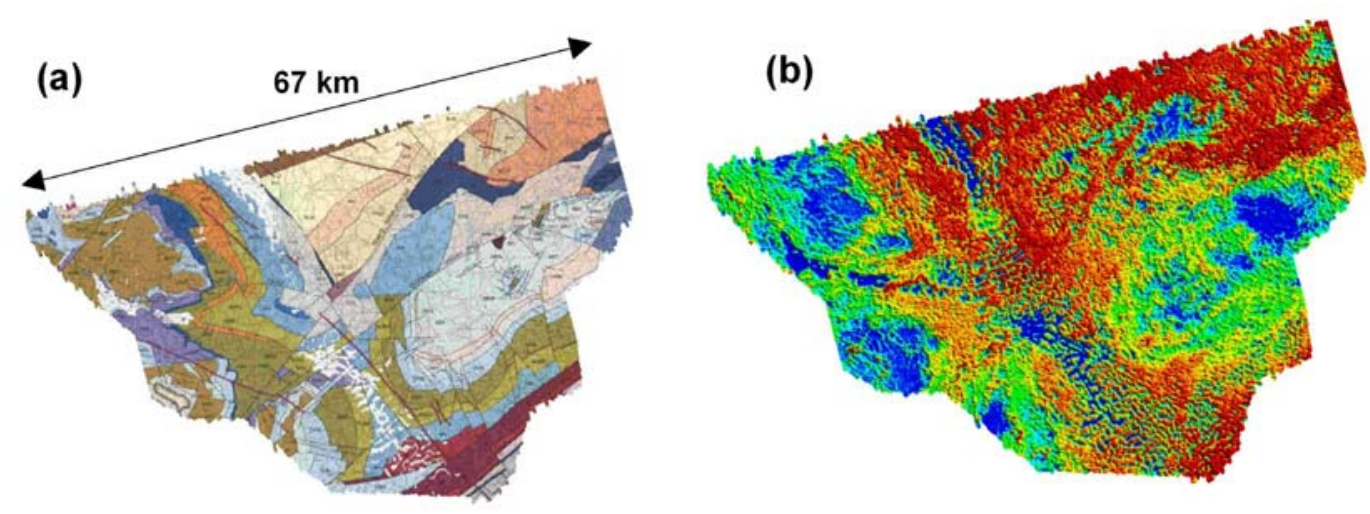

Figure 2. (a) Cut-out of 1:250k solid geology. (b) Radiometric total count for Block B.

The total radiometric counts, across the whole energy window, for survey Block B, are shown in Figure 2b. The data are shown alongside a cut-out of the $250 \mathrm{~K}$ solid geology map of Northern Ireland (Figure 2a). A comparison of the two images, at this scale of presentation, reveals that there are a wide number of strong correlations between the two. Peat covered ground occurs in association with low values (blue colour). Studies of peatland catchments may be afforded by combining both radiometric and conductivity data sets (e.g. Puranen et al., 1999).

\section{Electromagnetic (conductivity) data}

JAC procedures, as developed by GTK, include the calculation of apparent resistivity/conductivity and apparent depth, using the Fraser equivalent half-space (Suppala et al., 2005). These parameters, calculated at each frequency, provide the basic mapping capability of frequency-domain airborne EM. Previous studies (e.g. Beamish, 2004) indicate that at UK survey heights (CAA permitted), principal sensitivities to conductivity contrasts extend to about $60 \mathrm{~m}$ in depth. In the UK geological context, even the 2 frequency system can assess both superficial (e.g. Quaternary) and bedrock relationships. As previously noted, the high resolution mapping of the bulk conductivity of geological formations constitutes new national information. Figure 3a shows the $3 \mathrm{kHz}$ apparent conductivity obtained across Block B. The results can be compared with the solid geology map in Figure 2a. It is evident that, as with all geophysical measurements, the data do not 'simply' map geology. The material properties involved can be complex and there are cover/bedrock relationships (thicknesses) to be taken into account when interpreting single frequency information. One of the simplest features of Figure 3a are the lowest conductivities (black colours) that would be associated with the tightest (lowest porosity) formations. 


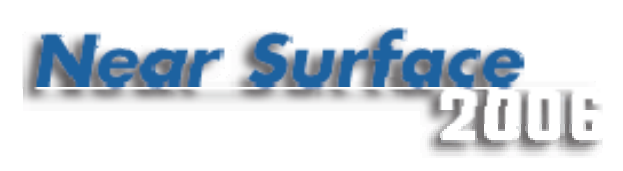

It is also evident that single formations, as mapped, may have non-uniform conductivities. It is possible to explore these associations further using slightly unconventional means. Figure $3 \mathrm{~b}$ is an image formed by taking the colours of the geological image (Figure 2a) and blending them with a shaded-relief image of the conductivity map of Figure 3a. The latter provides the high-wavenumber content of the lateral conductivity contrasts and is typically used to delineate faults, thrusts and offsets in geophysical data sets. Here, in Figure 3b, this functionality is well illustrated and, in addition, the variational conductivity 'fabric' of individual formations is emphasized and found to be equally revealing.
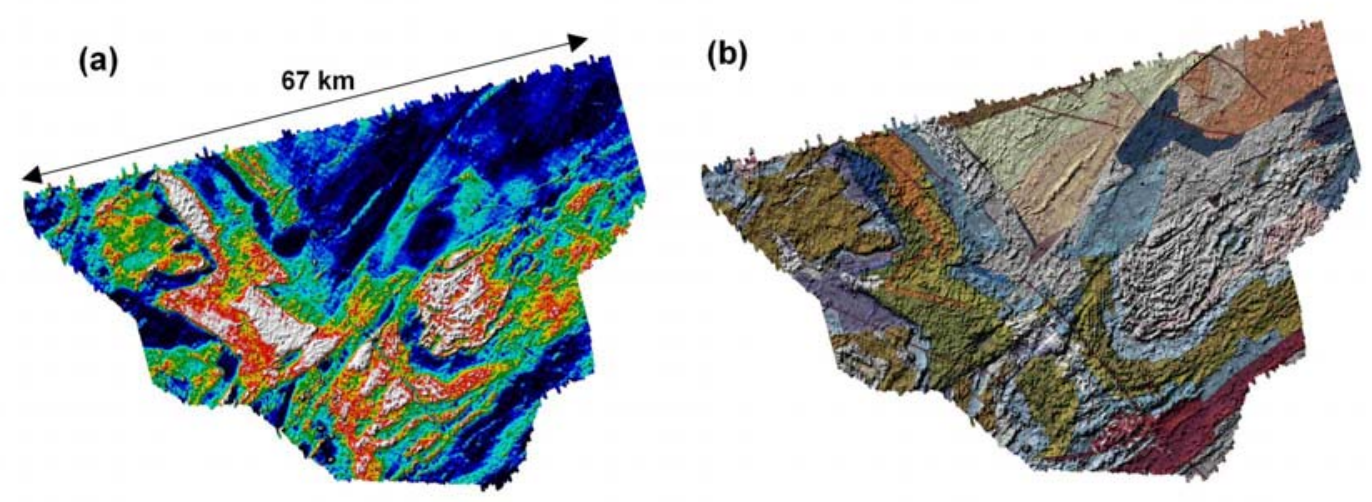

Figure 3. (a) 3kHz apparent conductivity of Block B. (b) Image formed by blending colours of geology with shaded-relief (NW sun angle) of the conductivity data in (a).

\section{References}

Beamish, D., 2004. Airborne EM skin depths. Geophysical Prospecting, 52, 439-449.

Hautaniemi, H., Kurimo, M., Multala, J., Leväniemi, H. and Vironmäki, J., 2005. The 'three in one' aerogeophysical concept of GTK in 2004. Geological Survey of Finland, Special paper 39, 21-74.

Hoover, D.B. and Pirece, H.A., 1990. Annotated bibliography of gamma-ray methods applied to gold exploration. U.S. Geological Survey, Open-File Report 90-203, 23pp.

Puranen, R., Säävuori, H., Sahala, L., Suppala, I., Mäkilä, M. and Lerssi, J. 1999. Airborne electromagnetic mapping of surficial deposits in Finland. First Break, May 1999, 145-154.

Suppala, I., Oksama, M. and Hongisto, H., 2005. GTK airborne EM system: characteristics and interpretation guidelines. Geological Survey of Finland, Special paper 39, 103-118. 